\title{
Comportamento comunicativo do docente de Enfermagem e sua influência na aprendizagem do educando
}

\author{
The Nursing professor's behavior in communication \\ and its influence on student learning
}

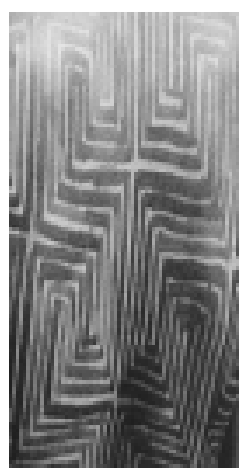

Este estudo é uma reflexão sobre o ensino de Enfermagem e a motivação que o aluno de graduação tem para o processo de ensino-aprendizagem. Sabendo-se que a motivação é uma condição interna do indivíduo e que o aprendizado não ocorre de forma isolada dos sentimentos ou das relações interpessoais $e$, sim, por processos carregados de afetividade, diferenças culturais, crenças e valores, realizamos este estudo com o objetivo de apreender os significados atribuídos à comunicação docente-discente no ensino de Enfermagem em sala de aula. O referencial teórico e metodológico desta pesquisa incluiu: a teoria de Rogers (1973), para justificar a maneira de perceber o processo de ensinoaprendizagem quando este dá ênfase às relações interpessoais e ao crescimento que delas resulta, centrado no indivíduo e em seus processos de construção e organização pessoal da realidade; e a proposta de observação dos sinais não-verbais de Silva (1996), quando descreve signos possíveis de serem identificados em nossa cultura de sala de aula. A pesquisa foi desenvolvida como estudo transversal e de campo das interações entre docente e alunos em sala de aula. Podemos afirmar, a partir dos resultados obtidos, que existem comportamentos comunicativos verbais e não-verbais que podem motivar o aluno a aprender. Os sujeitos pesquisados manifestaram-se referindo como aspectos facilitadores para o aprendizado: a dinâmica realizada em aula, a boa comunicação professor-aluno e o conteúdo relevante; como aspectos dificultadores: o tempo reduzido para a matéria, a inibição de alguns alunos e a falta de interesse pelo tema. Quando se observaram e observaram o outro, os sujeitos demonstraram a existência de coerência entre o verbal e não-verbal com gestos, posturas, expressões faciais e relações de distância interpessoal mantidas, complementando e até substituindo o verbal, além de demonstrar sentimentos. Os resultados deste estudo fazem-nos acreditar que a sala de aula pode ser um lugar de demonstração de emoção, descontração, afetividade e respeito pelo outro, onde as diferenças individuais devem ser reconhecidas, respeitadas e valorizadas, pois estimulam a construção do conhecimento.

Eliana Mara Rocha Dissertação de Mestrado, 1999 Programa de Pós-Graduação em Saúde do Adulto da Escola de Enfermagem, Universidade de São Paulo.

PALAVRAS-CHAVE: Ensino de Enfermagem; aprendizagem; comunicação não-verbal; comunicação em Enfermagem.

KEYWORDS: Nursing teaching; learning; non-verbal communication; Nursing communication.

PALABRAS-CLAVE:Enseñanza de Enfermería; aprendizaje; comunicación no verbal; comunicación en enfermería.

Recebido para publicação em: 02/10/00. Aprovado para publicação em: 20/10/00. 